\title{
Theoretical Study of Coupling Mechanism between FBG and Shock Waves of Rock Burst
}

\author{
Shiming Wei ${ }^{1,2}$, Zesheng Zhang ${ }^{1}$, Yao Wang1 \\ ${ }^{1}$ School of Energy Science and Engineering, Henan Polytechnic University, Jiaozuo, China \\ ${ }^{2}$ Collaborative Innovation Center of Coal Safety Production of Henan, Jiaozuo, China \\ Email: sming2002cn@163.com
}

How to cite this paper: Wei, S.M., Zhang, Z.S. and Wang, Y. (2020) Theoretical Study of Coupling Mechanism between FBG and Shock Waves of Rock Burst. World Journal of Engineering and Technology, 8, 784-791. https://doi.org/10.4236/wjet.2020.84057

Received: October 21, 2020

Accepted: November 22, 2020

Published: November 25, 2020

Copyright $\odot 2020$ by author(s) and Scientific Research Publishing Inc. This work is licensed under the Creative Commons Attribution International License (CC BY 4.0).

http://creativecommons.org/licenses/by/4.0/

\section{(c) (i) Open Access}

\begin{abstract}
To achieve the monitor of rock burst in coal mine with fiber Bragg grating (FBG) sensing, the coupling mechanism between FBG and shock waves was theoretically analyzed. Based on Housner's random shock model, the coupling mechanism between shock waves and FBG was theoretically analyzed. The result shows that the wave will change the period $\Lambda$ and effective refractive index $n$ of FBG, and further affect the initial wavelength value. The amplitude, phase and frequency of shock wave are directly related to the wavelength drifts of FBG. The transmitting velocity of shock wave in rock is affected by lithologic characteristics. The Elastic modulus, density and Poisson's ratio of rock influence the initial wavelength value of FBG. This study provided a theoretical basis and practical application guidance for coal or rock burst monitoring with FBG sensing.
\end{abstract}

\section{Keywords}

Rock Burst, FBG, Shock Waves, Lithological Characteristics

\section{Introduction}

With mining depth of China increasing gradually, the occurrence rate of rock burst also increases [1] [2]. The study of mechanism and prevention of rock burst have always been the focus in the field of mining engineering [3] [4] [5] [6]. Rock burst is often accompanied with strong mine earthquake [7] [8] [9], which transmits in coal and rock in the form of seismic waves with random energy. The energy level of shock waves is closely related to the occurrence of rock burst, and the higher the level of waves energy is, the greater the possibility of rock burst is. Thus, it becomes an important means to monitor earthquake waves for rock burst warning [10] [11] [12]. The following methods are often 
used: micro seismic, acoustic emission, electromagnetic radiation, etc. Jiang Fuxing et al. [13] developed the explosion-proof microseismic positioning monitoring system and carried it out in field application, which proved its feasibility in coal mine. Pan Yishan et al. [14] developed a monitoring and positioning system with kilometer-scale for breaking mine earthquake and analyzed the location of mine earthquake by picking up the vibration wave signals. The monitor was consistent with the earthquakes, which provided bases for mine disaster relief and loss reduction. Xie et al. [15] monitored the parameters of rock burst through acoustic emission, and obtained that the spatial distribution of microseismic events had fractal characteristics. Li Yuanhui et al. [16] studied the variation of $\mathrm{AE} \mathrm{b}$ and fractal dimension of spatial distribution under different stress levels in the process of rock fracture by acoustic emission, which improved the stability of stress monitoring of rock. Wang Enyuan et al. [17] [18] widely applied electromagnetic radiation technology in coal and rock dynamic disaster monitoring and early warning by studying electromagnetic radiation instrument. However, due to complex underground conditions, numerous large electrical equipments, serious electromagnetic interference, and the influence of water and gas, some of the above monitoring methods are invalid.

FBG is a kind of high-precision monitoring sensor sensing with wavelength drifts. Due to the merits of small size, anti-electromagnetic interference, corrosion resistance and so on, it has been widely used in many fields. Relevant researches show that the transmission process of shock waves after earthquake can be monitored by FBG. Peng Baojin et al. [19], based on tilted grating filter demodulation, studied a FBG microstrain sensing system, and the accuracy reached $0.009 \mu \varepsilon$. Wu Jianhui et al. [20], based on FBG sensing, set up a monitoring system of seismic wave with sensitivity of $0.54 \mathrm{pm} / \mathrm{ms}^{2}$. Because both earthquake and rock burst origin from sudden release of energy under high compressive stress concentration in rock, the shock waves generated are similar. Therefore, it is feasible to monitor rock burst of coal mine through FBG. Wang Jianda et al. [21] applied FBG sensing to underground coal mines, and developed early dynamic warning technology of rock burst as the early warning indexes of monitoring system of mining stress and stress gradient. Zhang Ningbo et al. [22] developed a multi-point stress and displacement monitoring system based on FBG sensing. Through experiments and engineering practice, the applicability of the system for rock burst in roadway was verified. Ginu Rajan et al. [23] adopted a high-frequency FBG testing system to monitor the high-frequency AE signals from stress-induced crack of rock samples with different shapes under compression load, and obtained the $\mathrm{AE}$ events consistent with the experiment, which revealed that high-frequency FBG can be used as a new technology for rock vibration monitoring. Gong $\mathrm{H}$ et al. [24] established a roof stability monitoring system in underground coal mine with FBG sensors, which verified the accuracy of FBG sensor in monitoring the strain of rock compression. Laudati et al. [25] designed a FBG triaxial acceleration sensor, and by measuring the axial deformation generated by dynamic acceleration of the fixture foundation, 
the lowest response frequency reached $0.1 \mathrm{~Hz}$, providing a technical tool for underground microseismic monitoring.

In general, the study of rock burst monitoring with FBG sensing is still in development, and it is only achieved to receive the dynamic signal of rock burst. However, the research on mechanism of FBG sensing for rock burst, especially the transmission characteristics and influencing factors of shock waves in different rock are not involved.

In this paper, based on the transmission characteristics of shock waves and the sensing principle of FBG, the coupling mechanism between the waves and FBG was studied. The purpose of study is to realize the monitor of rock burst in coal mine with FBG sensing, and get the factors affecting the monitoring accuracy.

\section{Mechanism of Lithologic Characteristics for Shock Wave Monitoring of Rock Burst with FBG Sensing}

\subsection{Coupling Mechanism between Shock Waves and FBG}

According to Housner's theory of random vibration [26], the ground motion was regarded as the superposition of randomly arriving pulses of a certain size:

$$
\alpha(t)=\sum_{k=1}^{N(t)} \eta \delta\left(t-t_{k}\right)
$$

where $\eta$ is a constant, $N(t)$ is the total number of pulses arriving between $[0, T], t_{k}$ is the random time of pulse arrival.

R. H. Scanlan and K. Sachs proposed to use Fourier series to simulate ground motion time history [27]:

$$
\alpha(t)=\sum_{k=1}^{N(t)} A_{k} \cos \left(\omega_{k} t-\phi_{k}\right)
$$

where $A_{k}$ is the amplitude spectrum value of the vibration time history; $\phi_{k}$ is the phase spectrum value of the vibration time history; $\omega_{k}$ is the frequency.

The sensing principle of FBG was analyzed and deduced based on coupled mode theory. By solving the wave equation with Maxwell's theory, the expression of wavelength of FBG was [28]:

$$
\lambda_{B}=2\left(n_{e f f}+\Delta n_{e f f}\right) \Lambda
$$

where $\lambda_{B}$ is the FBG reflected center wavelength, $n_{\text {eff }}$ and $\Lambda$ are the effective refractive index and grating period of the fiber core, respectively.

As shown in Figure 1, shock waves effect on FBG will change the period of the fiber core.

In combination with Equations (2) and (3), the changed refractive index period is [29]:

$$
\Lambda^{\prime}=\Lambda\left[1+\gamma \sum_{k=1}^{N(t)} A_{k} \cos \left(\omega_{k} t-\phi_{k}\right)\right]
$$

where, $\gamma$ is the coupling coefficient of random shock wave coupled with FBG. 


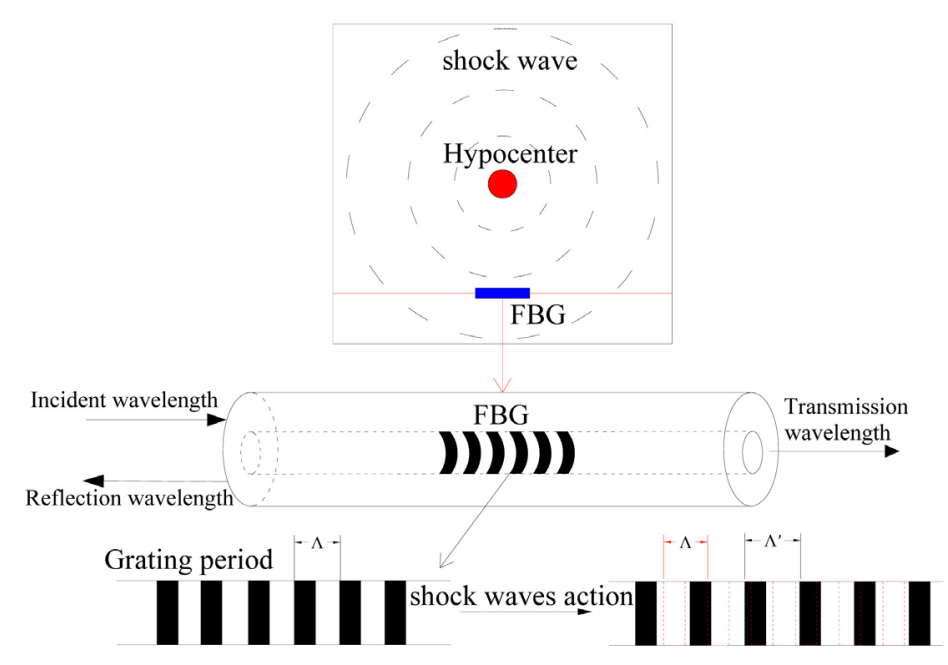

Figure 1. Coupling course between vibration shock wave and FBG.

From Equation (4), it can be obtained that when the random vibration wave is coupled with the fiber grating, the refractive index period of the original fiber grating will be redistributed.

Substitute $\Lambda^{\prime}$ into the central wavelength energy Formula (3):

$$
\lambda_{B}=2\left(n_{e f f}+\Delta n_{e f f}\right) \Lambda^{\prime} \approx 2 n_{e f f} \Lambda\left[1+\gamma \sum_{k=1}^{N(t)} A_{k} \cos \left(\omega_{k} t-\phi_{k}\right)\right]
$$

According to Equation (5), when shock waves of rock burst are monitored by the FBG sensor, the waves will be coupled with the FBG, and the initial wavelength of the FBG will be changed.

\subsection{Analysis of Influence Mechanism of Lithologic Characteristics}

According to Newton's law and Hooke's law, the rock generates volume and shape deformation under external forces. Two deformation spread in coal and rock by $\mathrm{P}$ and $\mathrm{S}$ wave. The movement direction of the $\mathrm{P}$-wave is the same to the spreading direction, while the $\mathrm{S}$-wave is perpendicular to the spreading direction.

The velocities $V_{P}$ of $\mathrm{P}$-wave and $V_{s}$ of S-wave can be respectively expressed as following [30]:

$$
\begin{gathered}
V_{p}=\sqrt{\frac{\lambda+2 \mu}{\rho}}=\sqrt{\frac{E(1-v)}{\rho(1+v)(1-2 v)}} \\
V_{s}=\sqrt{\frac{\mu}{\rho}}=\sqrt{\frac{E}{2 \rho(1+v)}}
\end{gathered}
$$

where $\lambda$ and $\mu$ are Lamé Constants, $E$ is the Elastic modulus, and $v$ is Poisson's ratio. $\lambda=\frac{E v}{2(1+v)(1-2 v)}, \quad \mu=\frac{E}{2(1+v)}$.

When the vibration wave spreads, the relation between wavelength and wave velocity is expressed as following: 


$$
V_{k}=\lambda_{k} \omega_{k}
$$

where $V_{k}$ is wave speed, and $\lambda_{k}$ is wavelength.

By comprehensive analysis of waveguide and elastic-optic effect, sensitivity of FBG under uniform transverse stress is smaller than longitudinal [31]. However, the phase difference of shock waves makes the transverse stress on FBG not uniform, and this results in axial strain improvement of sensitivity. Moreover, the attenuation speed of P-wave is faster than S-wave, and the amplitude of S-wave is larger than P-wave. Therefore, only the influence of transverse wave on FBG is considerable. Put Equations (7) and (8) into (5), it can be gotten as following:

$$
\lambda_{B}=2 n_{e f f} \Lambda\left[1+\gamma \sum_{k=1}^{N(t)} A_{k} \cos \left(\sqrt{\frac{2 E}{\rho(1+v)}} \frac{t}{2 \lambda_{k}}-\phi_{k}\right)\right]
$$

In order to study the influence of lithology characteristics on FBG monitoring shock wave, one random shock wave was taken for analysis, it meant that assuming $k=1$ in Equation (9). Assume $\phi_{k}=0$, and then get:

$$
\lambda_{B}=2 n_{e f f} \Lambda\left[1+\gamma A \cos \left(\sqrt{\frac{2 E}{\rho(1+v)}} \frac{t}{2 \lambda}\right)\right]
$$

According to Equation (10), when shock waves are monitored by FBG, the Elastic modulus, density, Poisson's ratio and other parameters of rock will affect its initial wavelength. That also means that when shock waves with same parameters spreads in different rock, the wavelength drifts are different, and the influence is in the form of cosine, as shown in Figure 2.

\section{Conclusions}

According to the analysis of the coupling mechanism between FBG and shock waves, the factors influencing initial wavelength of FBG are obtained, and the conclusions are as follows:

- The shock wave has coupling effect with FBG which will change its grating period and effective refractive index, thus finally affecting its initial wavelength. The amplitude, phase and frequency of the shock wave will directly affect the wavelength of FBG.

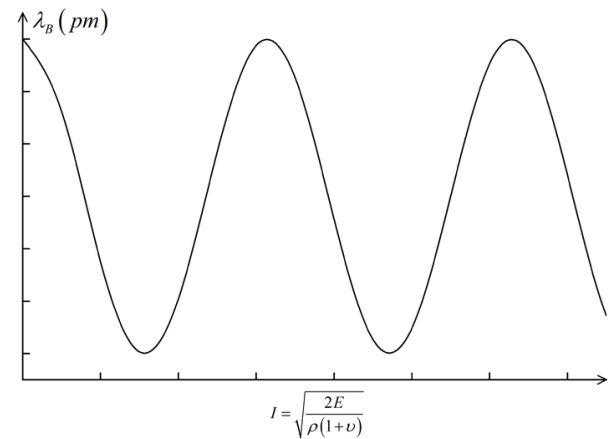

Figure 2. Relationship between lithologic parameters of rock and initial wavelength of FBG. 
- When shock waves with the same parameters in different rocks are monitored by FBG, the wavelength will be affected by the lithological characteristic parameter $I$, and has a cosine correlation with it. Therefore, as long as the rock mechanics parameters are obtained, the degree of influence of the lithological characteristics on the FBG monitoring can be obtained. This provides an important theoretical basis for coal or rock burst monitoring with FBG sensing, and can promote the application of optical test method for coal mine dynamic disaster.

\section{Acknowledgements}

This research was funded by National Natural Science Foundation of China (51674099).

\section{Conflicts of Interest}

The authors declare no conflicts of interest regarding the publication of this paper.

\section{References}

[1] Kang, H.-P., Wu, Y.-Z., He, J., et al. (2015) Rock Bolting Performance and Field Practice in Deep Roadway with Rock Burst. Journal of China Coal Society, 10, 2225-2233.

[2] Pan, Y.-S., Li, Z.-H. and Zhang, M.-T. (2003) Distribution, Type, Mechanism and Prevention of Rockburst in China. Chinese Journal of Rock Mechanics and Engineering, 11, 1844-1851.

[3] Dou, L.-M., Lu, C.-P., Mou, Z.-L., et al. (2005) Intensity Weakening Theory for Rockburst and Its Application. Journal of China Coal Society, 6, 690-694.

[4] Pan, Y.-S. (2018) Disturbance Response Instability Theory of Rockburst in Coal Mine. Journal of China Coal Society, 8, 2091-2098.

[5] Pan, J.-F., Liu, S.-H., Gao, J.M., et al. (2020) Prevention Theory and Technology of Rock Burst with Distinguish Dynamic and Static Load Sources in Deep Mine Roadway. Journal of China Coal Society, 5, 1607-1613.

[6] Qi, Q.-X., Pan, Y.-S., Li, H.-T., et al. (2020) Theoretical Basis and Key Technology of Prevention and Control of Coal-Rock Dynamic Disasters in Deep Coal Mining. Journal of China Coal Society, 5, 1567-1584.

[7] Dou, L.-M., Li, Z.-L. and Zhang, M. (2016) Study on Monitoring and Early Warning Technology of Mine Pressure Bump Disaster. Coal Science and Technology, 7, 41-46.

[8] Jiang, Y.-D., Pan, Y.-S., Jiang, F.-X., et al. (2014) State of the Art Review on Mechanism and Prevention of Coal Bumps in China. Journal of China Coal Society, 2, 205-213.

[9] Cao, A.-Y., Fan, J., Mu, Z.-L., et al. (2010) Burst Failure Effect of Mining-Induced Tremor on Roadway Surrounding Rock. Journal of China Coal Society, 12, 2006-2010.

[10] Qi, Q.-X., Ouyang, Z.-H., Zhao, S.-K., et al. (2014) Study on Types of Rock Burst Mine and Prevention Methods in China. Coal Science and Technology, 10, 1-5.

[11] Xia, Y.-X., Kang, L.-J., Qi, Q.-X., et al. (2010) Five Indexes of Microseismic and 
Their Application in Rock Burst Forecastion. Journal of China Coal Society, 12, 2011-2016.

[12] Jiang, F.-X., Yao, S.-L., Wei, Q.-D., et al. (2015) Study of Site Forewarn Mechanism of Rock Burst Induced by Shock Bump and Its Application. Chinese Journal of Rock Mechanics and Engineering, 34, 3372-3379.

[13] Jiang, F.-X., Yang, S.H., Cheng, Y.-H., et al. (2006) A Study on Microseismic Monitoring of Rock Burst in Coal Mine. Chinese Journal of Geophysics, 49, 1511-1516.

[14] Pan, Y.-S., Zhao, Y.-F., Guan, F.-H., et al. (2007) Study on Rockburst Monitoring and Orientation System and Its Application. Chinese Journal of Rock Mechanics and Engineering, 26, 1002-1011.

[15] Xie, H. and Pariseau, W.G. (1992) Studies on Mechanism of Rock Bursts-Associated Seismicity Mines by Using Fractals and Damage Mechanics. Proceedings of the 33 th US Rock Mechanics Symposium, 30, No, 4.

[16] Li, Y.-H., Liu, J.-P., Zhao, X.-D., et al. (2009) Study on B-Value and Fractal Dimension of Acoustic Emission during Rock Failure Process. Rock and Soil Mechanics, 30, 2559-2563+2574.

[17] Wang, E.-Y., Liu, X.-F., Li, Z.-H., et al. (2012) Application of Electromagnetic Radiation Technology in Monitoring and Warning on Coal and Rock Dynamic Disasters. Journal of Liaoning Technical University (Natural Science), 5, 642-645.

[18] He, X.-Q., Nei, B.-S., Wang, E.-Y., et al. (2007) Electromagnetic Emission Forecasting Technology of Coal or Rock Dynamic Disasters in Mine. Journal of China Coal Society, 1, 56-59.

[19] Peng, B.J., Shen, Y.Q., Ying, C.F., et al. (2009) Novel Detection System for Micro-Strain Signal Based on Demodulation Method of Tilted Fiber Bragg Grating Sensors. Proceedings of SPIE, The International Society for Optical Engineering, 4th International Symposium on Advanced Optical Manufacturing and Testing Technologies: Optical Test and Measurement Technology and Equipment, Vol. 7283, 19 November 2008-21 November 2008.

[20] Wu, J.H., Yang, K.T., Xiang, Q.L., et al. (2008) Nuclear Explosion Seismic Wave Detection Based on the Fiber Bragg Grating Geophone. Photonics and Optoelectronics Meetings, Vol. 7278, 1-7.

[21] Wang, J.-D., Qin, K., Deng, Z.-G., et al. (2019) Study on Early Warning Technology of Rock Burst Based on Mining Stress Monitoring by Fiber Grating. Coal Science and Technology, 6, 126-132.

[22] Zhang, N.-B., Wang, J.-D., Qin, K., et al. (2020) The Evaluation Technology of Coal Bump Risk in Excavation Roadway Based on Multi-Point Stress and Displacement Monitoring System. Journal of China Coal Society, 1-11.

[23] Rajan, G. and Karekal, S. (2017) High Frequency Fiber Bragg Grating Interrogator for Monitoring Rock Cracking Events for Mining Applications. 2017 2nd International Conference for Fibre-Optic and Photonic Sensors for Industrial and Safety Applications, Brisbane, 8-10 January 2017, 45-51.

https://doi.org/10.1109/OFSIS.2017.12

[24] Gong, H., Kizil, M.S., Chen, Z., et al. (2017) Validation of Bare FBG Sensors in Monitoring Compressive Rock Mass Deformation. 2017 2nd International Conference for Fibre-Optic and Photonic Sensors for Industrial and Safety Applications, Brisbane, 8-10 January 2017, 85-90. https://doi.org/10.1109/OFSIS.2017.20

[25] Laudati, A., Mennellaa, F. and Espositoa, M. (2008) A Fiber Optic Grating Seismic Sensor. IEEE Photonics Technology Letters, 24, 1991-1993. 
https://doi.org/10.1109/LPT.2007.909628

[26] Housner, G.W. (1947) Characteristics of Strong Motion Earthquake. Bulletin of the Seismogical Society of America, 1, 19-31.

[27] Scanlan, R. and Sachs, H.K. (1974) Earthquake Time Histories and Response Spectra. Journal of Engineering Mechanics Division, 4, 635-655.

[28] Wei, S.-M. (2008) Study on Theory and Method of Fiber Bragg Grating Sensing in Rock Deformation Test. PhD Dissertation, Xi'an University of Science and Technology, Xi'an.

[29] Hu, Z.-X. (2013) Research of Monitoring Seismic Waves Methods Based on FBG. M.D. Dissertation, University of Electronic Science and Technology of China, Chengdu.

[30] Gibowicz, S.J. and Kijko, A. (1994) An Introduction to Mining Seismology. Academic Press, San Diego.

[31] Wang, Y. (2018) Study of FBG Sensing Methods and Analysis of Its Influence Factors for Earthquake Shock Wave Monitor. M.D. Dissertation, Henan Polytechnic University, Jiaozuo. 